\title{
Imbalance-Voltage Mitigation in an Inverter-Based Distributed Generation System Using a Minimum Current- Based Control Strategy
}

\begin{tabular}{|r|l|}
\hline Journal: & IEEE Transactions on Power Delivery \\
\hline Manuscript ID & TPWRD-00141-2019.R1 \\
\hline Manuscript Type: & Transactions \\
\hline Author: & 09-Jun-2019 \\
\hline Complete List of Authors: & $\begin{array}{l}\text { Moradi Ghahderijani, Mohammad; Universitat Politecnica de Catalunya, } \\
\text { ingeniera de electronica } \\
\text { Camacho, Antonio; Universitat Politecnica de Catalunya Escola } \\
\text { Politecnica Superior d'Enginyeria de Vilanova i la Geltru, Automatic } \\
\text { Control Department } \\
\text { Moreira, C.; INESC TEC-INESC Technology and Science, } \\
\text { Castilla, Miguel; Tech Univ Catalonia, Electronic Engineering Department } \\
\text { Garcia de Vicuna, Jose; Technical University of Catalonia, Electronic } \\
\text { Engineering }\end{array}$ \\
\hline Technical Topic Area : & Distributed resources < Transmission and Distribution \\
\hline Key Words: & Distributed generation, Voltage control, Negative sequence voltage \\
\hline
\end{tabular}

\section{SCHOLARONE ${ }^{m}$ \\ Manuscripts}




\title{
Imbalance-Voltage Mitigation in an Inverter-Based Distributed Generation System Using a Minimum Current-Based Control Strategy
}

\author{
M. Moradi Ghahderijani, Antonio Camacho, Carlos Moreira, Miguel Castilla, and Luis García de Vicuña
}

\begin{abstract}
Voltage imbalances are one of the most severe challenges in electrical networks, which negatively affect their loads and other connected equipment. This paper proposes a voltage support control strategy to mitigate the voltage imbalance in inverter-based low voltage distribution networks. The control scheme is derived taking in mind the following control objectives: a) to increase the positive sequence voltage as much as possible, b) to decrease the negative sequence voltage as much as possible, c) to inject the power generated by the primary source, and d) to minimize the output current of the inverter. The innovative contribution of the proposed solution is based on the design of a control algorithm that meets the aforementioned objectives without resorting to communications with other grid components. The theoretical results are experimentally validated by selected tests on a laboratory setup with $X / R$ ratio close to one.
\end{abstract}

Index Terms - Inverter-based distributed generation, voltage imbalance, voltage support.

\section{INTRODUCTION}

$\mathrm{N}$ OWADAYS, power quality issues are of most concern in all electrical networks. Voltage imbalances are one of the most severe perturbations that can occur for long periods of time or even that exist constantly in the network. This problem may happen due to faults in generation side, an unmatched impedance in transformers or the most common reason in the costumer side, i.e. connecting large single-phase loads on the three-phase networks as well as a result of integration of small scale generation systems in low voltage grids [1].

Based on IEEE standard, voltage imbalance is defined as a ratio of the negative to the positive sequence voltage value [2]. Furthermore, there are various standards to limit the maximum value of the voltage imbalance. For instance, ANSI C84.1 has suggested a $3 \%$ voltage imbalance value, while in the United States, the maximum value is restricted to $2.5 \%$. And, in more stringent case, the national equipment manufacturers association (NEMA MG-1) requires motors to operate safely in an imbalance voltage less than $1 \%$ [3].

These strict standards can be feasible using inverter-based distributed generators (DG). The key part in these converters is the control scheme. Voltage support control based on symmetric sequences is a well-accepted solution in literature [4]-[12]. The basis of this solution is the decomposition of the unbalanced voltages into the positive and negative sequence voltages. In this method, the controller calculates the current references for positive and negative sequences using the symmetric voltage components. These current references rely on the selected control objectives [13]-[17]. In [13], a symmetric-sequence based control strategy has been proposed for a wind power system under voltage dips. Authors in [15] have proposed a symmetric-sequence based control strategy aiming to handle the delivered instantaneous power under imbalanced voltage sag. The control objectives in these papers are not comprehensive to cover all aspects at the same time. Furthermore, most of them focuses on mitigating short-term voltage sags in mainly inductive grids (high voltage networks) [18]-[21].

However, few research has been carried out to consider the effect of long-term imbalance voltage in medium or low voltage networks with some inherent resistive behavior [22]-[25]. In addition, the controllers in these papers are highly dependent on the system parameters, or at least an exact value of the $\mathrm{X} / \mathrm{R}$ ratio must be known or be estimated to be used in control strategy.

The main focus of this paper is the selection of the current references for an inverter-based DG operating in a power system with voltage imbalance. The idea is to propose a communication-less voltage support control algorithm based only on local measurements at the inverter terminals, giving the main contribution of this paper. A low voltage network is emulated by selecting the line impedances so that the $\mathrm{X} / \mathrm{R}$ ratio is selected close to one. The novelty of this approach is that the control strategy is not dependent on the system parameters. In other word, the controller can mitigate the long term voltage imbalance or even short term voltage sags independently of line impedances and load values.

The control objectives considered in this paper are: a) to increase the positive sequence voltage as much as possible (typically to reach 1 p.u.), b) to decrease the negative sequence voltage as much as possible, c) to inject the power generated by the primary source, and d) to minimize the output current of the inverter. As far as authors know, there are no previous studies exploring these four objectives together for low voltage

This work was supported by the Ministry of Economy and Competitiveness of Spain and by the European Regional Development Fund under project RTI2018100732-B-C22.

M. Moradi is with the Department of Electronic Engineering, Technical University of Catalonia, 08800 Barcelona, Spain (e-mail: mmghahderijani@ yahoo.com) A. Camacho is with the Automatic Control Department, Technical University of Catalonia, 08800 Barcelona, Spain (e-mail: antonio.camacho.santiago@ upc.edu) C. Moreira is with the Center for Power and Energy Systems of INESC TEC, Porto, Portugal (e-mail: carlos.moreira@inesctec.pt)

M. Castilla is with the Department of Electronic Engineering, Technical University of Catalonia, 08800 Barcelona, Spain (e-mail: miquel.castilla@ upc.edu)

L. Garcia de Vicuña is with the Department of Electronic Engineering, Technical University of Catalonia, 08800 Barcelona, Spain (e-mail: vicuna@ eel.upc.edu) 


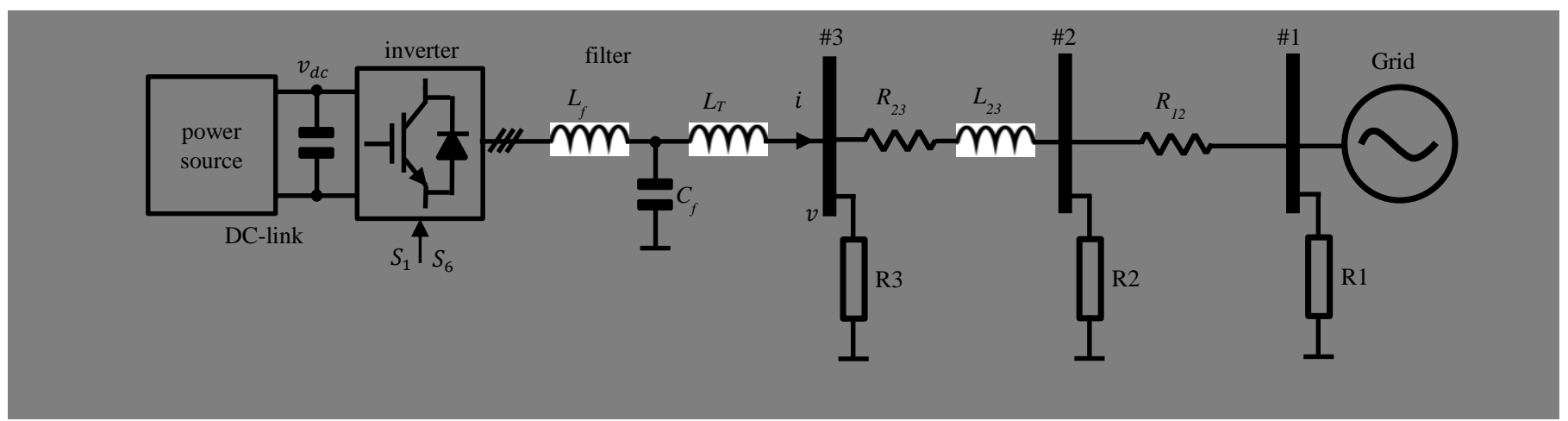

Fig. 1. Diagram of an inverter-based distributed generation system connected to a 3-bus power system.

networks. The aim of the first control objective is to support the positive sequence voltage by only injecting positive sequence currents. Complementarily, the second control objective is dedicated to minimize the voltage imbalance ratio by the injection of the necessary negative sequence current. The third control objective aims to efficiently exploit the power production of the installation. Finally, the four control objective tries to minimize the amplitude of the injected currents of the inverter. This objective helps to improve the power characteristics by reducing the amount of current that the inverters must inject in a scenario with unbalanced voltages. Furthermore, better voltage results can be achieved without risk of overcurrent tripping. All these control objectives are formulated mathematically in the paper and then the current references for the symmetric sequence components are derived according to their fulfillment. Moreover, selected experimental results are presented to validate that the four control objectives are reached successfully.

The rest of the paper is structured as follows. Section II describes the power plant under study. Section III introduces the basic control scheme under voltage imbalance. Section IV formulates the problem by defining the control objectives mathematically and then presents the control strategy to solve the problem. Section $\mathrm{V}$ verifies the theoretical contributions by selected experimental results in a laboratory setup. Finally, Section VI gives the conclusions.

\section{POWER PLANT DESCRIPTION}

Fig. 1 shows the diagram of an inverter-based distributed generation system connected to a 3-bus distribution grid. The power source is connected to bus \#3 through a full-power inverter and an isolation transformer $\left(L_{T}\right)$. Note that to reduce noise and switching harmonics, the output of the inverter is connected to an $\mathrm{LC}$ filter $\left(L_{f}-C_{f}\right)$. The focus of this paper is to improve the power quality in bus \#3, where the control strategy is applied. This bus is connected to the public grid through line impedances between bus \#2 and \#3 and bus \#1 and \#2. The total line impedance between the inverter and grid is considered neither inductive nor resistive, so that the corresponding $\mathrm{X} / \mathrm{R}$ ratio has been selected close to one (see the numerical values provided in Section V). In this case, a low voltage grid is emulated. In addition, one three-phase local load is connected to each bus. It is worth mentioning that the local load 2 is used to emulate the voltage imbalance condition, so that one of its phases is disconnected. In this way, the positive sequence voltages at bus \#2 and \#3 are decreased while the negative sequences are increased compared with the voltages in the balanced condition. Therefore, the voltage at bus \#3 is unbalanced. This issue will be further explained in Section V.

\section{CONTROL STRUCTURE}

This section explains the basic control concepts required to introduce the proposed approach.

Fig. 2(a) shows the overall control scheme developed for voltage support. As shown, the first step is to sense the instantaneous local current and voltage variables $i, v$, and $v_{d c}$. Afterward, Clarke transformation is used to obtain the $\alpha \beta$ representation of the three-phase variables. In addition, to decompose the voltage $v$ into the symmetric sequences, a Second Order Generalized Integrator (SOGI)-based voltage sequence extractor is applied [26], [27]. The output of the SOGI gives the online values of the positive and negative sequence voltages $v_{\alpha}^{+}, v_{\alpha}^{-}, v_{\beta}^{+}$, and $v_{\beta}^{-}$. According to these values, the amplitudes of the positive and negative sequences and the angle between them are computed as

$$
\begin{gathered}
V^{+}=\sqrt{\left(v_{\alpha}^{+}\right)^{2}+\left(v_{\beta}^{+}\right)^{2}} \\
V^{-}=\sqrt{\left(v_{\alpha}^{-}\right)^{2}+\left(v_{\beta}^{-}\right)^{2}} \\
\varphi_{V}=\operatorname{atan} 2\left(v_{\alpha}^{+} v_{\alpha}^{-}-v_{\beta}^{+} v_{\beta}^{-}, v_{\alpha}^{+} v_{\beta}^{-}+v_{\alpha}^{-} v_{\beta}^{+}\right)
\end{gathered}
$$

where the atan2 function calculates the two argument arctangent values.

The current reference generator gives the current references in $\alpha \beta$ domain. These currents can be expressed as [17]

$$
\begin{aligned}
& i_{\alpha}^{*}=i_{\alpha(p)}^{*}+i_{\alpha(q)}^{*} \\
& i_{\beta}^{*}=i_{\beta(p)}^{*}+i_{\beta(q)}^{*}
\end{aligned}
$$

where

$$
\begin{aligned}
i_{\alpha(p)}^{*} & =\frac{v_{\alpha}^{+}}{V^{+}} I_{p}^{+}+\frac{v_{\alpha}^{-}}{V^{-}} I_{p}^{-} \\
i_{\beta(p)}^{*} & =\frac{v_{\beta}^{+}}{V^{+}} I_{p}^{+}+\frac{v_{\beta}^{-}}{V^{-}} I_{p}^{-} \\
i_{\alpha(q)}^{*} & =\frac{v_{\beta}^{+}}{V^{+}} I_{q}^{+}+\frac{v_{\beta}^{-}}{V^{-}} I_{q}^{-} \\
i_{\beta(q)}^{*} & =-\frac{v_{\alpha}^{+}}{V^{+}} I_{q}^{+}-\frac{v_{\alpha}^{-}}{V^{-}} I_{q}^{-}
\end{aligned}
$$




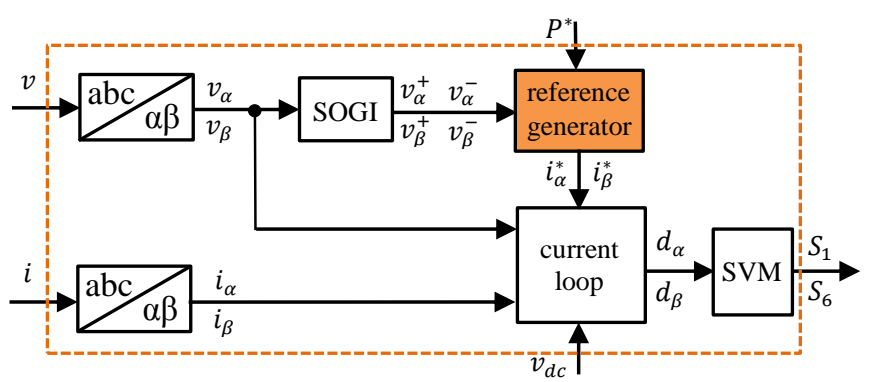

(a)

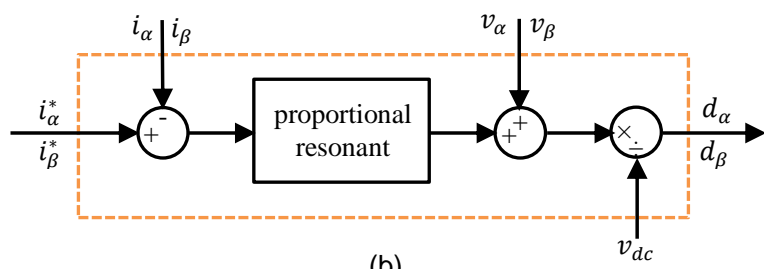

(b)

Fig. 2. Control structure of a three-phase inverter under voltage imbalance: a) overall structure, b) current loop details.

and $I_{p}^{+}, I_{p}^{-}, I_{q}^{+}$, and $I_{q}^{-}$are the positive and negative amplitudes of the active and reactive current references. The derivation of the appropriate values of these amplitude variables that meet the desired control objectives is the main contribution of this paper. This derivation is carried out in Section IV.

Still in Fig. 2(a), the current loop is responsible for eliminating the error between the measured currents $\left(i_{\alpha}\right.$ and $\left.i_{\beta}\right)$ and the reference currents $\left(i_{\alpha}^{*}\right.$ and $\left.i_{\beta}^{*}\right)$. To this end, this block provides the suitable duty cycle variables $d_{\alpha}$ and $d_{\beta}$. Finally, the gate signals for power switches $S_{1}$ to $S_{6}$ are computed by the space vector modulator (SVM).

Fig. 2(b) details the implementation of the current control loop. A proportional-resonant controller regulates the inverter current. In addition, the output and dc-link voltages are feedforward terms to accelerate the transient response of this control loop [25].

\section{CONTROL PROPOSAL}

In this section, the control objectives are first formulated mathematically and then the current reference generator that meets these objectives is derived.

\section{A. Control Objectives}

The control proposal formulates four different objective functions related to $V^{+}, V^{-}, P^{*}$ and $I_{\max }=\max \left(I_{a}, I_{b}, I_{c}\right)$, where $P^{*}$ is the power generated by the primary source and $I_{a}, I_{b}, I_{c}$ are the amplitudes of the phase currents injected by the inverter. Hence, the control objectives are

$$
\begin{gathered}
V^{+}=\left(V^{+}\right)^{*} \\
V^{-}=\left(V^{-}\right)^{*} \\
P^{*}=P^{+}+P^{-} \\
\min \left\{I_{\max }\right\}
\end{gathered}
$$

where $\left(V^{+}\right)^{*}$ and $\left(V^{-}\right)^{*}$ are the references for the amplitudes of the sequence voltages and $P^{+}$and $P^{-}$are the injected active powers via positive and negative sequences, respectively. The

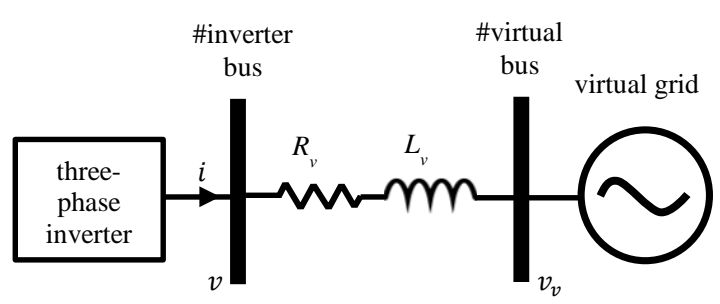

Fig. 3. Diagram of the virtual power system.

main idea of the voltage support proposed in this paper is to regulate the voltage $V^{+}$and $V^{-}$at the terminals of the inverter to their references $\left(V^{+}\right)^{*}$ and $\left(V^{-}\right)^{*}$ according to (10) and (11). In addition, this voltage support must be done while the inverter injects the generated power (12) with the minimum value of the current $I_{\max }$ (13).

\section{B. Control Derivation}

This subsection derives the equations that relates the currents $I_{p}^{+}, I_{p}^{-}, I_{q}^{+}$and $I_{q}^{-}$with the control objectives (10) to (13).

In the derivation, the first step uses the concept of virtual power system. The idea is to formulate the equation of the power system assuming that the converter is connected to a virtual grid $v_{v}$ through a virtual line with components $R_{v}$ and $L_{v}$, as shown in Fig. 3. The validity of this idea lies in the integral compensation that the proposed control inherently performs, as demonstrated in the next section. Based on the voltage support concept developed in the literature, the voltage at the virtual bus can be written as [28], [29]

$$
\begin{aligned}
& V_{v}^{+}=V^{+}-R_{v} I_{p}^{+}-\omega L_{v} I_{q}^{+} \\
& V_{v}^{-}=V^{-}-R_{v} I_{p}^{-}+\omega L_{v} I_{q}^{-}
\end{aligned}
$$

where $V_{v}^{+}$and $V_{v}^{-}$are the positive and negative sequence amplitudes of the virtual voltage $v_{v}$. In (14) and (15), $R_{v}$ and $L_{v}$ are control parameters. The initial values of these parameters are the impedance values seem at the output terminals of the inverter. In Section V, design guidelines for these parameters are presented.

The second step guarantees the injection of the power produced by the primary source. To this end, the positive and negative sequence active powers can be written as [25]

$$
\begin{aligned}
& P^{+}=\frac{3}{2} V^{+} I_{p}^{+} \\
& P^{-}=\frac{3}{2} V^{-} I_{p}^{-} .
\end{aligned}
$$

From (16) and (17), the control objective (12) can be written as

$$
P^{*}=\frac{3}{2}\left(V^{+} I_{p}^{+}+V^{-} I_{p}^{-}\right)
$$

The last step is to find the equations that minimize the inverter output current, as expressed in (13). The phase between the positive and negative sequences of this current $\varphi_{I}$ is a key parameter to achieve this objective. Fig. 4 shows an example of how the currents $I_{a}, I_{b}, I_{c}$ and $I_{\max }$ vary as a function of this phase. The Appendix shows the equations necessary to draw the 


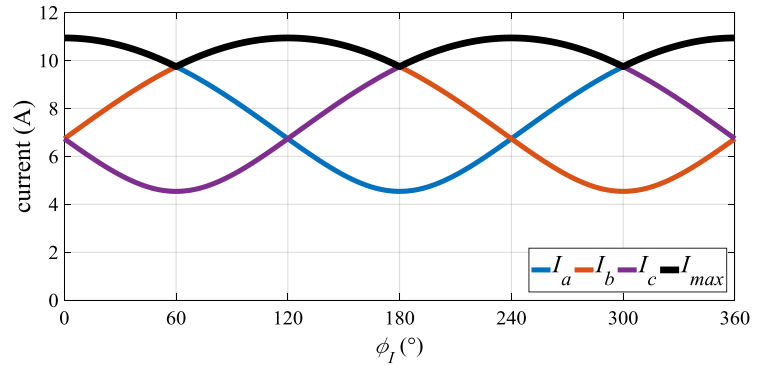

Fig. 4. Phase current amplitudes and maximum current as a function of the phase $\varphi_{I}$.

figure; see (A4)-(A9). This example uses the steady-state values of the currents $I_{p}^{+}, I_{p}^{-}, I_{q}^{+}$and $I_{q}^{-}$measured in the test 1 of the experimental results. From this figure, it is clear that the control objective (13) is reached for three particular values of $\varphi_{I}^{*}=60^{\circ}$, $180^{\circ}, 300^{\circ}$, which must satisfy (see Appendix)

$$
\varphi_{I}^{*}=-\varphi_{V}+\operatorname{atan} 2\left(I_{q}^{+}, I_{p}^{+}\right)+\operatorname{atan} 2\left(I_{q}^{-}, I_{p}^{-}\right) .
$$

It is worth mentioning that (19) relates the current amplitude variables with the phase between the positive and negative sequences of the current.

Note that (14), (15), (18), and (19) forms a nonlinear system of four equations and four unknowns $\left(I_{p}^{+}, I_{p}^{-}, I_{q}^{+}\right.$and $\left.I_{q}^{-}\right)$. The following subsection shows the way in which this system has been solved in this work.

\section{Control Solution}

The algorithm that computes the current references is shown in Fig. 5. First, the amplitudes $V^{+}$and $V^{-}$and the phase $\varphi_{V}$ are calculated using (1)-(3). Next, the amplitudes $V_{v}^{+}$and $V_{v}^{-}$are obtained from (14) and (15) by using the current amplitudes of the previous iteration $I_{p(-1)}^{+}, I_{p(-1)}^{-}, I_{q(-1)}^{+}$and $I_{q(-1)}^{-}$.

The active currents $I_{p}^{+}$and $I_{p}^{-}$are responsible for achieving the control objectives (12) and (13). The $I_{\max }$ current takes the minimal value when the angle $\varphi_{I}^{*}$ is $60^{\circ}, 180^{\circ}$ or $300^{\circ}$, as discussed above (see Fig. 4). The value of $I_{p}^{-}$is obtained by solving (19) and selecting $\varphi_{I}^{*}$ as follows

$$
\varphi_{I}^{*}=\left\{\begin{aligned}
60^{\circ}, & -30^{\circ} \leq \varphi_{V}^{\prime}<90^{\circ} \\
180^{\circ}, & 90^{\circ} \leq \varphi_{V}^{\prime}<210^{\circ} \\
300^{\circ}, & 210^{\circ} \leq \varphi_{V}^{\prime}<330^{\circ}
\end{aligned}\right.
$$

where $\varphi_{V}^{\prime}=\varphi_{V}-\operatorname{atan} 2\left(I_{q}^{+}, I_{p}^{+}\right)$; see lines 9 to 13 in Fig. 5 . The value of $I_{p}^{+}$is found by solving (18), which guarantees that the inverter injects to the grid the power generated by the primary source.

The reactive currents $I_{q}^{+}$and $I_{q}^{-}$are responsible for regulating the inverter output voltage according to the control objectives (10) and (11). The values for these currents are obtained by solving (14) and (15) and using the voltage references $\left(V^{+}\right)^{*}$ and $\left(V^{-}\right)^{*}$ instead of voltages $V^{+}$and $V^{-}$.

A current limitation mechanism is included in the algorithm in order to limit the maximum current injected by the inverter. The first aim of this mechanism is to protect the inverter from overcurrent. In this emergency situation, the priority is to inject
FUNC: $\left(i_{\alpha}^{*}, i_{\beta}^{*}\right)=$ VoltageSupport $\left(v_{\alpha}^{+}, v_{\alpha}^{-}, v_{\beta}^{+}, v_{\beta}^{-}, P^{*}\right)$
$1 \%$ Local voltage at bus \#3

$2 V^{+}=\operatorname{sqrt}\left(\left(v_{\alpha}^{+}\right)^{2}+\left(v_{\beta}^{+}\right)^{2}\right)$

$3 V^{-}=\operatorname{sqrt}\left(\left(v_{\alpha}^{-}\right)^{2}+\left(v_{\beta}^{-}\right)^{2}\right)$

$4 \varphi_{V}=\operatorname{atan} 2\left(v_{\alpha}^{+} v_{\alpha}^{-}-v_{\beta}^{+} v_{\beta}^{-}, v_{\alpha}^{+} v_{\beta}^{-}+v_{\alpha}^{-} v_{\beta}^{+}\right)$

$5 \%$ Voltage at the virtual bus

$6 V_{v}^{+}=V^{+}-R_{v} I_{p(-1)}^{+}-\omega L_{v} I_{q(-1)}^{+}$

$7 V_{v}^{-}=V^{-}-R_{v} I_{p(-1)}^{-}+\omega L_{v} I_{q(-1)}^{-}$

$8 \%$ Minimum current Imax

$9 \varphi_{V}^{\prime}=\varphi_{V}-\operatorname{atan} 2\left(I_{q(-1)}^{+}, I_{p(-1)}^{+}\right)$

10 if $-30^{\circ} \leq \varphi_{V}^{\prime} \leq 90^{\circ}$ then $\varphi_{I}^{*}=60^{\circ}$

11 if $90^{\circ} \leq \varphi_{V}^{\prime} \leq 210^{\circ}$ then $\varphi_{I}^{*}=180^{\circ}$

12 if $210^{\circ} \leq \varphi_{V}^{\prime} \leq 330^{\circ}$ then $\varphi_{I}^{*}=300^{\circ}$

$13 I_{p}^{-}=I_{q(-1)}^{-} / \tan \left(\varphi_{I}^{*}+\varphi_{V}-\operatorname{atan} 2\left(I_{q(-1)}^{+}, I_{p(-1)}^{+}\right)\right)$

$14 I_{p}^{+}=\left((2 / 3) P^{*}-V^{-} I_{p}^{-}\right) / V^{+}$

$15 \%$ Reactive current amplitudes

$16 I_{q}^{+}=\left(\left(V^{+}\right)^{*}-V_{v}^{+}-R_{v} I_{p}^{+}\right) /\left(\omega L_{v}\right)$

$17 I_{q}^{-}=\left(V_{v}^{-}-\left(V^{-}\right)^{*}+R_{v} I_{p}^{-}\right) /\left(\omega L_{v}\right)$

$18 \%$ Overcurrent protection

$19 I^{+}=\sqrt{\left(I_{p}^{+}\right)^{2}+\left(I_{q}^{+}\right)^{2}}$

$20 I^{-}=\sqrt{\left(I_{q}^{-}\right)^{2}+\left(I_{q}^{-}\right)^{2}}$

$21 \varphi_{I}=-\varphi_{V}+\operatorname{atan} 2\left(I_{q}^{+}, I_{p}^{+}\right)+\operatorname{atan} 2\left(I_{q}^{-}, I_{q}^{-}\right)$

$22 I_{a}=\sqrt{\left(I^{+}\right)^{2}+\left(I^{-}\right)^{2}+2 I^{+} I^{-} \cos \left(\varphi_{I}\right)}$

$23 I_{b}=\sqrt{\left(I^{+}\right)^{2}+\left(I^{-}\right)^{2}+2 I^{+} I^{-} \cos \left(\varphi_{I}-2 / 3 \pi\right)}$

$24 I_{c}=\sqrt{\left(I^{+}\right)^{2}+\left(I^{-}\right)^{2}+2 I^{+} I^{-} \cos \left(\varphi_{I}+2 / 3 \pi\right)}$

$25 I_{\max }=\max \left(I_{a}, I_{b}, I_{c}\right)$

26 if $I_{\max }>I_{s c}$ then $I_{p}^{+}=\min \left(\frac{2 P^{*}}{3 V^{+}}, I_{s c}\right), I_{p}^{-}=0, I_{q}^{+}=0, I_{q}^{-}=0$

$27 \%$ Update of the current amplitudes for the next iteration

$28 I_{p(-1)}^{+}=I_{p}^{+} ; I_{p(-1)}^{-}=I_{p}^{-} ; I_{q(-1)}^{+}=I_{q}^{+} ; I_{q(-1)}^{-}=I_{q}^{-}$

$29 \%$ Reference currents

$30 i_{\alpha}^{*}=v_{\alpha}^{+} I_{p}^{+} / V^{+}+v_{\alpha}^{-} I_{p}^{-} / V^{-}+v_{\beta}^{+} I_{q}^{+} / V^{+}+v_{\beta}^{-} I_{q}^{-} / V^{-}$

$31 i_{\beta}^{*}=v_{\beta}^{+} I_{p}^{+} / V^{+}+v_{\beta}^{-} I_{p}^{-} / V^{-}-v_{\alpha}^{+} I_{q}^{+} / V^{+}-v_{\alpha}^{-} I_{q}^{-} / V^{-}$

$32 \operatorname{return}\left(i_{\alpha}^{*}, i_{\beta}^{*}\right)$

Fig. 5. Algorithm for the proposed current reference generator.

the short circuit current $I_{s c}$ (as an assumption, 1.5 times larger than the nominal current). The second aim is to maintain the active power injection, when possible, in order to do not disturb the operation of the power source. In this case, the imbalancevoltage mitigation cannot be guaranteed. Taking these priorities in mind, the current references are calculated as:

$$
\begin{gathered}
I_{p}^{+}=\min \left(\frac{2 P^{*}}{3 V^{+}}, I_{s c}\right) \\
I_{p}^{-}=0 \\
I_{q}^{+}=0 \\
I_{q}^{-}=0
\end{gathered}
$$

With these current references, the minimum current injection is maintained in the emergence situation by following a different approach. When $I_{p}^{+}=2 P^{*} / 3 V^{+}$, the inverter injects the power reference $P^{*}$. When $I_{p}^{+}=I_{s c}$, the inverter enters in a power limitation mode as a result of reaching the maximum 


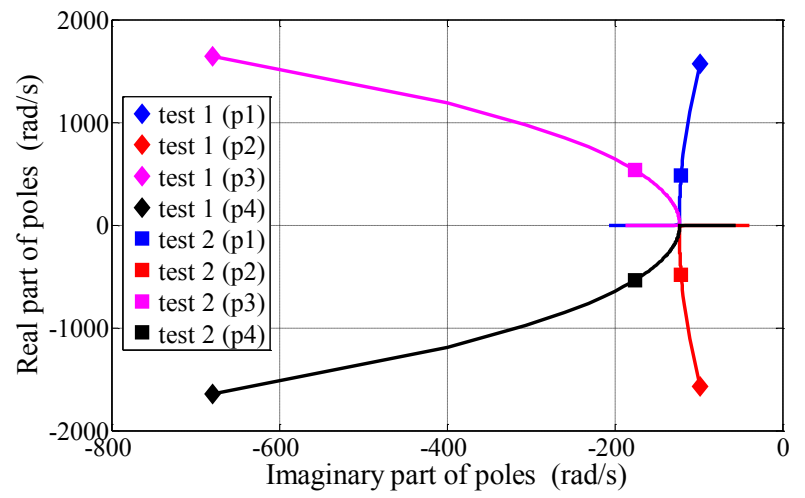

Fig. 6. Location of the closed-loop poles as a function of $\lambda$.

current and injects an active power lower than the power reference.

Note that, in addition to maintaining the active power injection, it is worth mentioning that other options can be selected for the second aim of the current limitation mechanism. In this paper, this particular objective is chosen as an illustrative example, to demonstrate the effectiveness and robustness of the proposed solution. The search for alternative mechanisms of current limitation is left for future work.

Finally, the reference currents are calculated in $\alpha \beta$ domain using (4)-(9).

\section{CONTROL Design}

The reference generator proposed in the previous Section has two control parameters $R_{v}$ and $L_{v}$. Below guidelines to design these parameters are presented.

The nonlinear control system is linearized around a steadystate operating point using a classical small-signal linearization technique named perturbation and linearization approach. This technique is based on assuming that the variables and independent inputs can be expressed as constant DC values plus small AC variations. By replacing these variables in the original nonlinear system and considering that the nonlinear terms are much smaller than the linear AC terms, then a linear model can be derived. Interested readers can be found more details in linearizing approach in [30].

This analysis reveals the features of the proposed control. For instance, the voltage support is performed by an adaptive integral compensator

$$
\begin{aligned}
& \hat{I}_{q}^{+}=k_{i}^{+} \int\left(\left(\hat{V}^{+}\right)^{*}-\hat{V}^{+}\right) d t \\
& \hat{I}_{q}^{-}=k_{i}^{-} \int\left(\left(\hat{V}^{-}\right)^{*}-\hat{V}^{-}\right) d t
\end{aligned}
$$

where

$$
\begin{gathered}
k_{i}^{+}=\frac{1}{T\left(R_{v} k^{+}+\omega L_{v}\right)} \\
k_{i}^{-}=\frac{1}{T\left(R_{v} k^{-}+\omega L_{v}\right)} \\
k^{+}=\frac{-V_{S S}^{-} I_{p S S}^{+}\left(I_{S S}^{-}\right)^{2}}{V_{S S}^{+} I_{q S S}^{-}\left(I_{S S}^{+}\right)^{2}-V_{s S}^{-} I_{q S S}^{+}\left(I_{S S}^{-}\right)^{2}} \\
k^{-}=\frac{V_{s S}^{+} I_{p S S}^{-}\left(I_{s S}^{+}\right)^{2}}{V_{S S}^{+} I_{q S S}^{-}\left(I_{S S}^{+}\right)^{2}-V_{s S}^{-} I_{q S S}^{+}\left(I_{s S}^{-}\right)^{2}} .
\end{gathered}
$$

TABLE I SYSTEM PARAMETERS

\begin{tabular}{cccc}
\hline \hline Parameter & Symbol & Nominal Value & $\begin{array}{c}\text { Per-Unit } \\
\text { Value }\end{array}$ \\
\hline Inverter rated power & $S_{b}$ & $7.5 \mathrm{kVA}$ & 1 \\
Grid voltage (line- & $v_{g}$ & $230 \mathrm{Vrms}$ & 1 \\
neutral) & $f_{g}$ & $50 \mathrm{~Hz}$ & - \\
Grid frequency & $I_{s c}$ & $16.3 \mathrm{Arms}$ & 1.5 \\
Short circuit current & $v_{d c}$ & $690 \mathrm{~V}$ & 3 \\
DC-link voltage & $L_{f}$ & $1.2 \mathrm{mH}$ & 0.018 \\
Filter inductance & $C_{f}$ & $1.6 \mu \mathrm{F}$ & 0.011 \\
Filter capacitor & $L_{T}$ & $1 \mathrm{mH}$ & 0.015 \\
Transformer inductance & $R_{l 2}$ & $0.68 \Omega$ & 0.032 \\
Line resistance 12 & $L_{23}$ & $3.5 \mathrm{mH}$ & 0.052 \\
Line inductance 23 & $R_{23}$ & $1.22 \Omega$ & 0.035 \\
Line resistance 23 & $R_{I}$ & $20 \Omega$ & 0.945 \\
Load 1 & $R_{2}$ & $10 \Omega$ & 0.473 \\
Load 2 & $R_{3}$ & $17 \Omega$ & 0.803 \\
Load 3 & $P^{*}$ & $3 \mathrm{~kW}$ & 0.4 \\
Switching frequency & $f_{s}$ & $18 \mathrm{kHz}$ & - \\
Sampling Time & $T$ & $55.55 \mu \mathrm{s}$ & - \\
\hline \hline
\end{tabular}

TABLE II

TEST SCENARIOS

\begin{tabular}{cccccc}
\hline \hline Test & $\left(V^{+}\right)^{*}(\mathrm{~V})$ & $\left(V^{-}\right)^{*}(\mathrm{~V})$ & $\lambda$ & $R_{v}(\Omega)$ & $L_{v}(\mathrm{mH})$ \\
\hline \multirow{2}{*}{$\mathbf{1}$} & 310 & 5 & 1 & 1.9 & 3.5 \\
& $(0.953$ p.u. $)$ & $(0.015$ p.u. $)$ & & $(0.09$ p.u. $)$ & $(0.052$ p.u. $)$ \\
\hline \multirow{2}{*}{$\mathbf{2}$} & 310 & 5 & \multirow{2}{*}{3} & 5.7 & 10.5 \\
& $(0.953$ p.u. $)$ & $(0.015$ p.u. $)$ & & $(0.269$ p.u. $)$ & $(0.156$ p.u. $)$ \\
\hline \multirow{3}{*}{3} & 310 & 1 & 3 & 5.7 & 10.5 \\
\hline \hline
\end{tabular}

In (25)-(30), the symbol ${ }^{\wedge}$ means small-signal variables, the subscript $s s$ denotes steady-state value and $T$ is the sampling time used in the digital controller that implements the control algorithm. The adaptability of the integral gains to the steadystate operating point can be clearly seen in (27) and (28). The details to derive these expressions are omitted here due to space limitations.

The linearized system has four poles whose location depend on the values of $R_{v}$ and $L_{v}$. Fig. 6 shows the location of these poles using the component values of the experimental tests and varying the parameter $\lambda$ from 1 to 30

$$
\begin{aligned}
R_{v} & =\lambda R_{v o} \\
L_{v} & =\lambda L_{v o}
\end{aligned}
$$

being $R_{v o}$ and $L_{v o}$ the values of the virtual impedance used in test 1 defined as

$$
\begin{gathered}
R_{v o}=R_{12}+R_{23} \\
L_{v o}=L_{23} .
\end{gathered}
$$

Note that the performance of the solution is robust and independent from the loads either because the X/R factor is dominated by the lines and because of the robustness of the controller itself with respect to the variation of the parameter $\lambda$.

For low values of $\lambda$, two pairs of complex conjugate poles are 


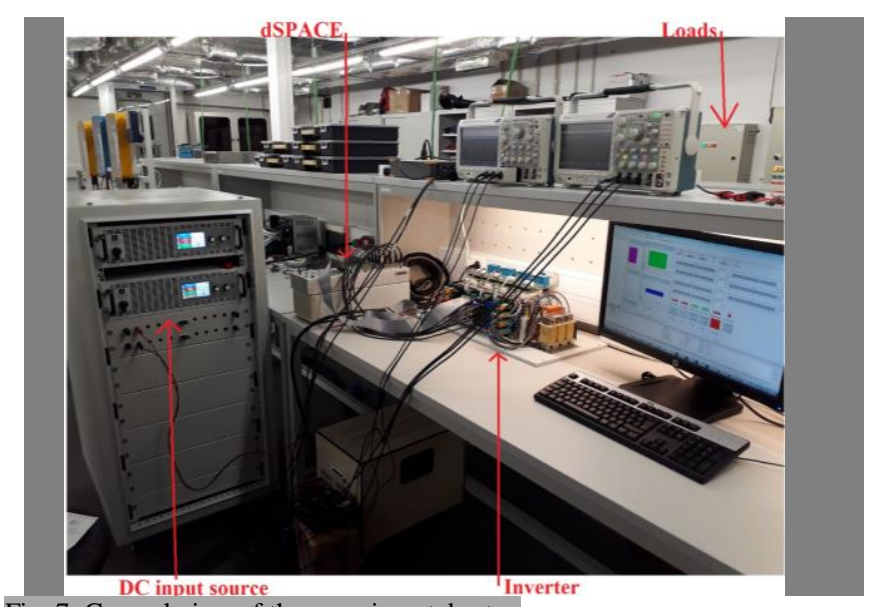

Fig. 7. General view of the experimental setup

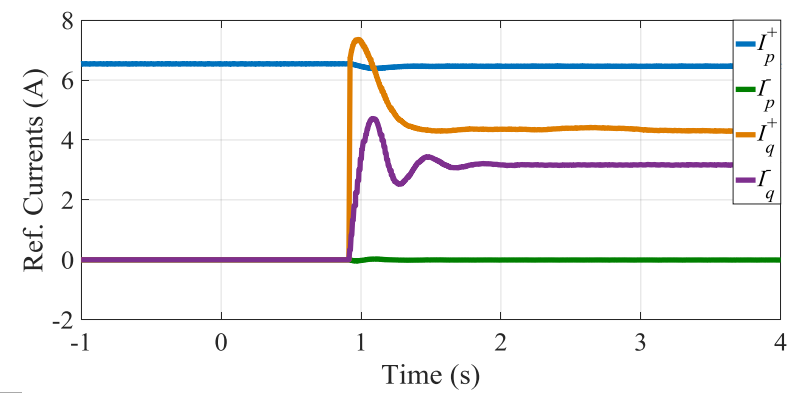

Fig. 8. Reference currents in Test 1.

observed. In particular, for $\lambda=1$ (test 1 ), $\mathrm{p} 1$ and $\mathrm{p} 2$ are dominant and the converter behaves as an equivalent second order linear system. However, the damping factor is low and a transient response with overshoots and oscillations is expected. The dynamics improve when $\lambda$ increases, but the high frequency poles approach the low frequency poles and there are no dominant poles. For $\lambda=3$ (test 2), a transient response with low overshoot is expected. The four poles become real for high $\lambda$ values. Two of these poles (p2 and $\mathrm{p} 4$ ) approach the origin which slows down the transient response of the system.

A good trade-off between low overshoot and fast transient response can be reached by designing $\lambda$ in the range 3 to 10 in the example considered in this study. These predictions are validated by experimental results in next Section.

\section{EXPERIMENTAL RESULTS}

Based on Fig. 1, a laboratory setup has been built to verify the dynamic and static performance of the proposed control strategy against the voltage imbalance conditions. Fig.7 shows the general view of the setup.

\section{A. Description of Laboratorial Facilities}

The line impedances in Fig. 1, i.e., $R_{12}, R_{23}$ and $L_{23}$ were emulated by using three-phase resistive LV $(400 / 230 \mathrm{~V})$ cable simulators. The loads $R_{I}$ to $R_{3}$ were implemented with threephase controllable resistive banks with the maximum nominal power of $27 \mathrm{~kW}$. The inverter was a three-phase $7.5 \mathrm{kVA} / 400$ $\mathrm{V}$ inverter. The control algorithm was implemented in MATLAB Simulink and compiled in dSPACE_DS1103 to program the inverter prototype. Furthermore, ControlDesk

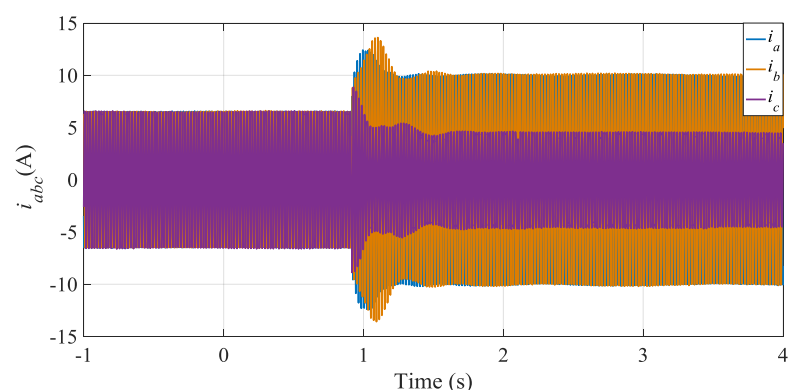

(a)

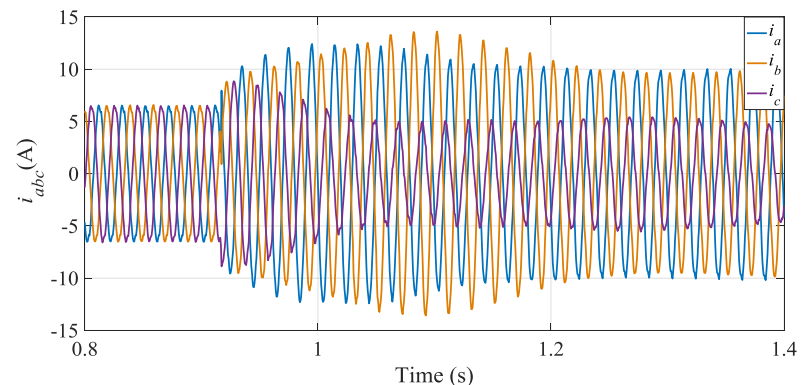

(b)

Fig. 9. (a) phase currents injected by the inverter in Test 1, (b) zoom-in of the above waveforms.

software was used for signal monitoring purposes. The nominal values of the system parameters along with their Per Unit values are summarized in Table I ( $\left.S_{\text {base }}=7.5 \mathrm{kVA} V_{\text {base }}=230 \mathrm{~V}\right)$.

\section{B. Test Conditions}

The voltage imbalance was emulated by disconnecting one of the phases of load 2. In this case, the voltage unbalance factor $\left(V U F=V^{-} / V^{+}\right)$measured at the inverter output was $4 \%$.

The aim of the control strategy is to reduce the VUF as much as possible while meeting all the control objectives defined in Section IV.A. To evaluate the performance of the proposed control strategy, three different test scenarios were considered as listed in Table II. In Test 1, the references for the peak values of the positive and negative sequence voltages are set to $\left(V^{+}\right)^{*}=310 \mathrm{~V}$ and $\left(V^{-}\right)^{*}=5 \mathrm{~V}$, respectively. In addition, the virtual impedance was chosen with the same value as the existing line impedance $R_{v o}$ and $L_{v o}(\lambda=1)$. To evaluate the robustness of the proposed control strategy, in Test 2 , the value of virtual impedance was set three times higher than the nominal value of the existing line impedance $(\lambda=3)$. And finally, the reference $\left(V^{-}\right)^{*}$ was set to $1 \mathrm{~V}$ in Test 3 to show the ability of the proposed control to virtually eliminate the negative sequence voltage.

\section{Experimental Results}

Fig. 8 shows the reference currents in Test 1 . The positive and negative sequences of the reactive currents are $I_{q}^{+}=4.2 \mathrm{~A}$ and $I_{q}^{-}=3.2 \mathrm{~A}$. These currents are responsible to force the output voltages of the inverter to reach their desired values $\left(V^{+}=310 \mathrm{~V}\right.$ and $\left.V^{-}=5 \mathrm{~V}\right)$. Furthermore, the positive sequence current is $I_{p}^{+}=6.4 \mathrm{~A}$. This current ensures the third control objective to inject all the active power generated by the 


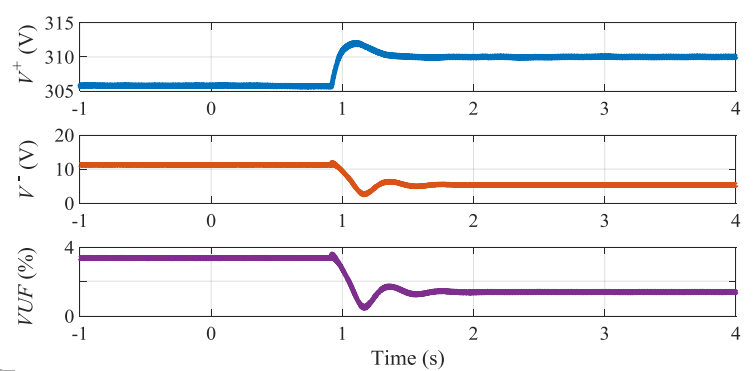

Fig. 10. Positive and negative sequence voltages and voltage unbalance factor in Test 1.

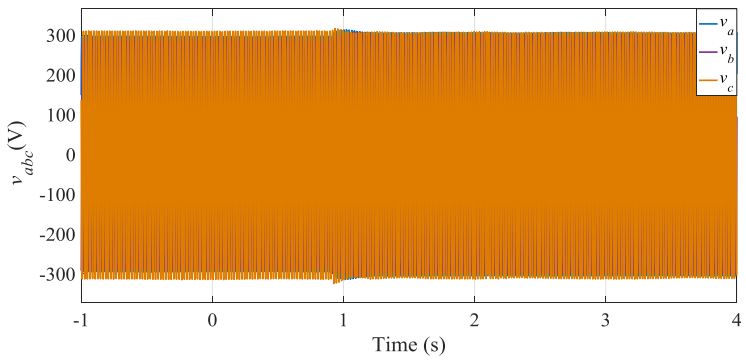

(a)

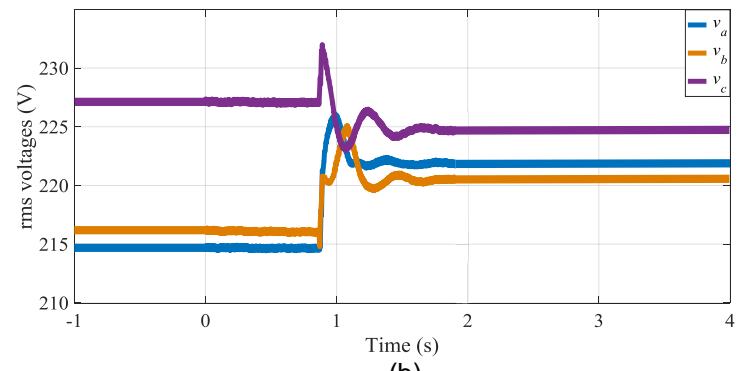

(b)

Fig. 11. Voltages at bus \#3 in Test 1: (a) Phase voltages (b) rms voltages.

primary source $(P=3 \mathrm{~kW})$. The last control objective is achieved by the proper selection of the negative sequence active current $I_{p}^{-}$. This current is set close to $0 \mathrm{~A}$ based on the method explained in Section IV.C. Therefore, the active power is injected practically through the positive sequence.

The settling time of these waveforms is approximately $0.8 \mathrm{~s}$. This is the time necessary for all references to reach the steady state. The location of the poles of the closed loop system, shown in Fig. 6, is responsible for this transient response. Note that, with this settling time, the impact of the practical implementation of the control is negligible. For example, the SOGI-based sequence extractor has a response time of about 20 ms. In addition, the estimated delay for the operation of the control algorithm is two sampling periods (i.e., $111 \mathrm{us}$ ).

Fig. 9 shows the phase currents in Test 1. As shown in Fig. $4, I_{\text {max }}$ reaches its minimum value when two of the currents have the same amplitude and the other phase has a lower amplitude. This behavior can be seen in Fig. 8 when the currents are in steady state, which guarantees that the generated power is injected with the minimum value of the phase currents.

Fig. 10 shows the positive and negative sequence voltages and the VUF in Test 1. Before activating the control strategy, the positive and negative sequence voltages are $V^{+}=305 \mathrm{~V}$ and $V^{-}=10 \mathrm{~V}$, respectively ( $\mathrm{VUF} \approx 3.3 \%$ ). By activating the
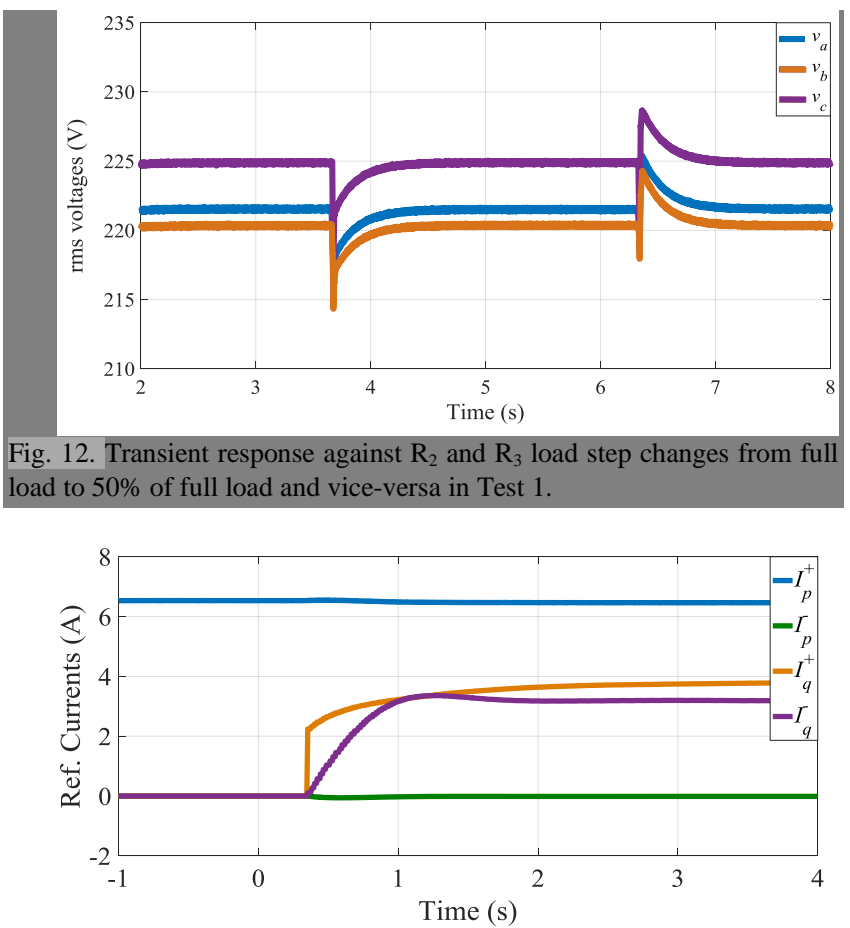

Fig. 13. Reference currents in Test 2.

control at $t \approx 1 \mathrm{~s}$, these voltages reach their reference values yielding a VUF $\approx 1.6 \%$, with a settling time of around $0.8 \mathrm{~s}$.

The phase voltages and their corresponding rms values are shown in Fig. 11. Note in Fig. 11(b) that a clear reduction in voltage imbalance is reached when the proposed control is activated.

Fig. 12 shows the transient response to load step changes. The load resistors R2 and R3 were changed from full to $50 \%$ of full load and viceversa. The proposed control reacts to this change by adapting the reference currents in real time, resulting in a transient deviation of about $5 \mathrm{~V}$ with a settling time around 0.5 s. Note that, in steady state, the phase voltages are independent of the load condition, thus confirming the adaptive integral compensation performed by the proposed control; see (25) and (26).

Next the selected results for Test 2 are presented and discussed. Fig. 13 shows the injected active and reactive currents through the positive and negative sequences. Compared to Test 1 , the steady-state values of $I_{p}^{+}, I_{p}^{-}$and $I_{q}^{-}$ nearly coincide. The only difference is a reduction in the value of $I_{q}^{+}$from $4.2 \mathrm{~A}$ to $3.7 \mathrm{~A}$. In addition, the transient response improves as predicted in Section V.

Fig. 14 shows the phase currents in Test 2. As indicated above, two amplitudes of the currents coincide in steady-state and the third amplitude has a lower value, which allows to affirm that the stated objectives are achieved with the minimum current (see Fig. 4).

Finally the results obtained for the positive and negative sequence voltages $V^{+}$and $V^{-}$and the voltage unbalance factor is depicted in Fig. 15. Note that an improved dynamic response (settling time of $0.4 \mathrm{~s}$ but without any overshoot) is obtained using $\lambda=3$ instead of $\lambda=1$, as predicted theoretically. 


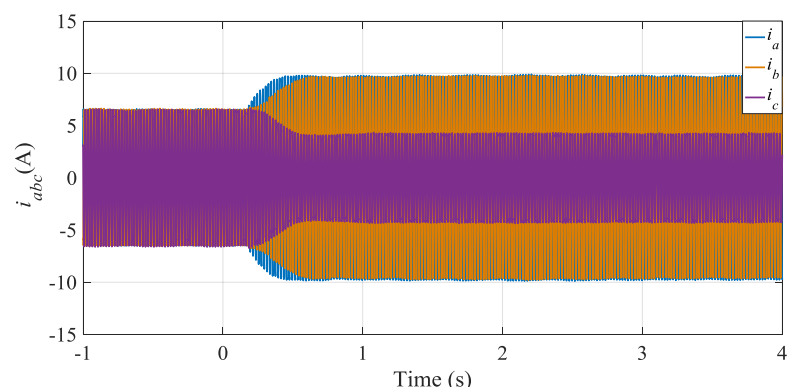

(a)

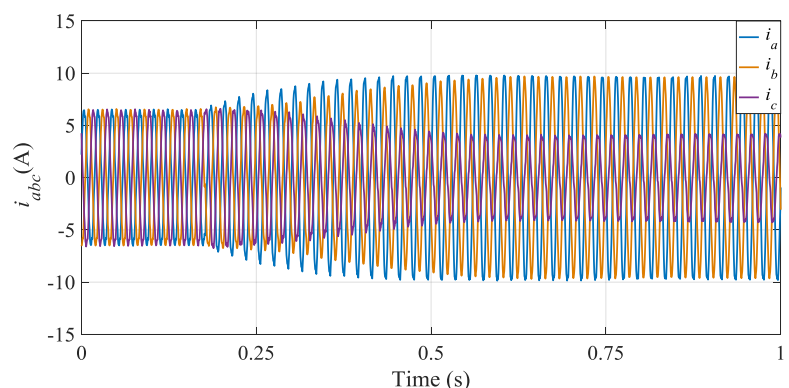

(b)

Fig. 14. (a) phase currents injected by the inverter in Test 2, (b) zoom-in of the above waveforms.
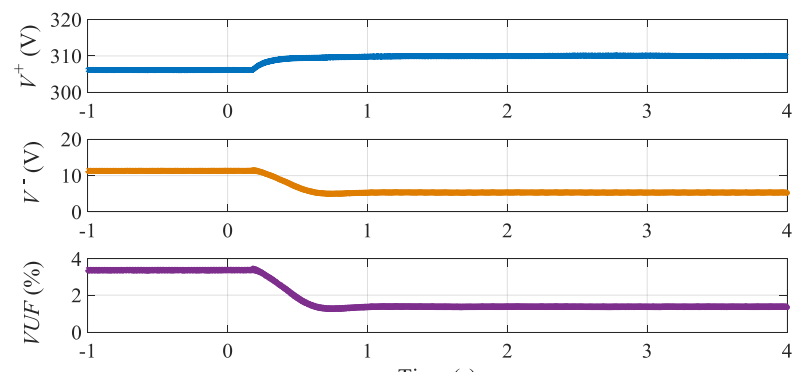

Time (s)

Fig. 15. Positive and negative sequence voltages and voltage unbalance factor in Test 2.
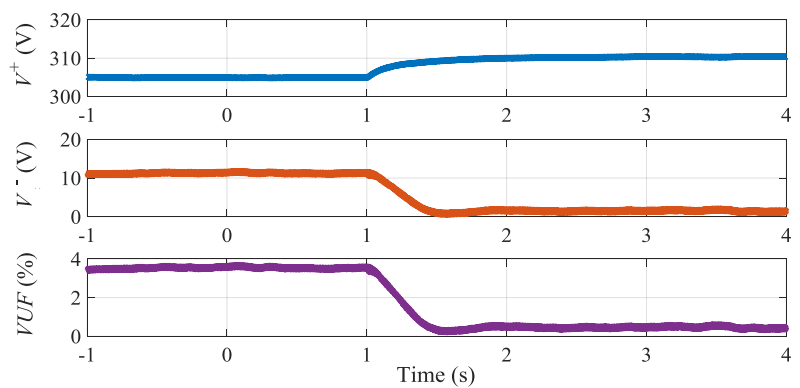

Fig. 16. Positive and negative sequence voltages and voltage unbalance factor in Test 3.

The third test confirms the capacity of the proposed control to almost eliminate the voltage imbalance. To this end, the reference voltage $\left(V^{-}\right)^{*}$ is set to $1 \mathrm{~V}$. Fig. 16 shows the positive and negative voltage amplitudes and the VUF for Test 3 . Note that the desired value for $V^{-}$is reached, giving a VUF $=0.3 \%$, but with a slightly slower dynamic response (settling time of $0.5 \mathrm{~s}$ ). However, this value meets all the standards indicated in Section I.

Finally, the performance of the proposed control is evaluated during a voltage sag. Fig. 17(a) shows the phase voltages. In
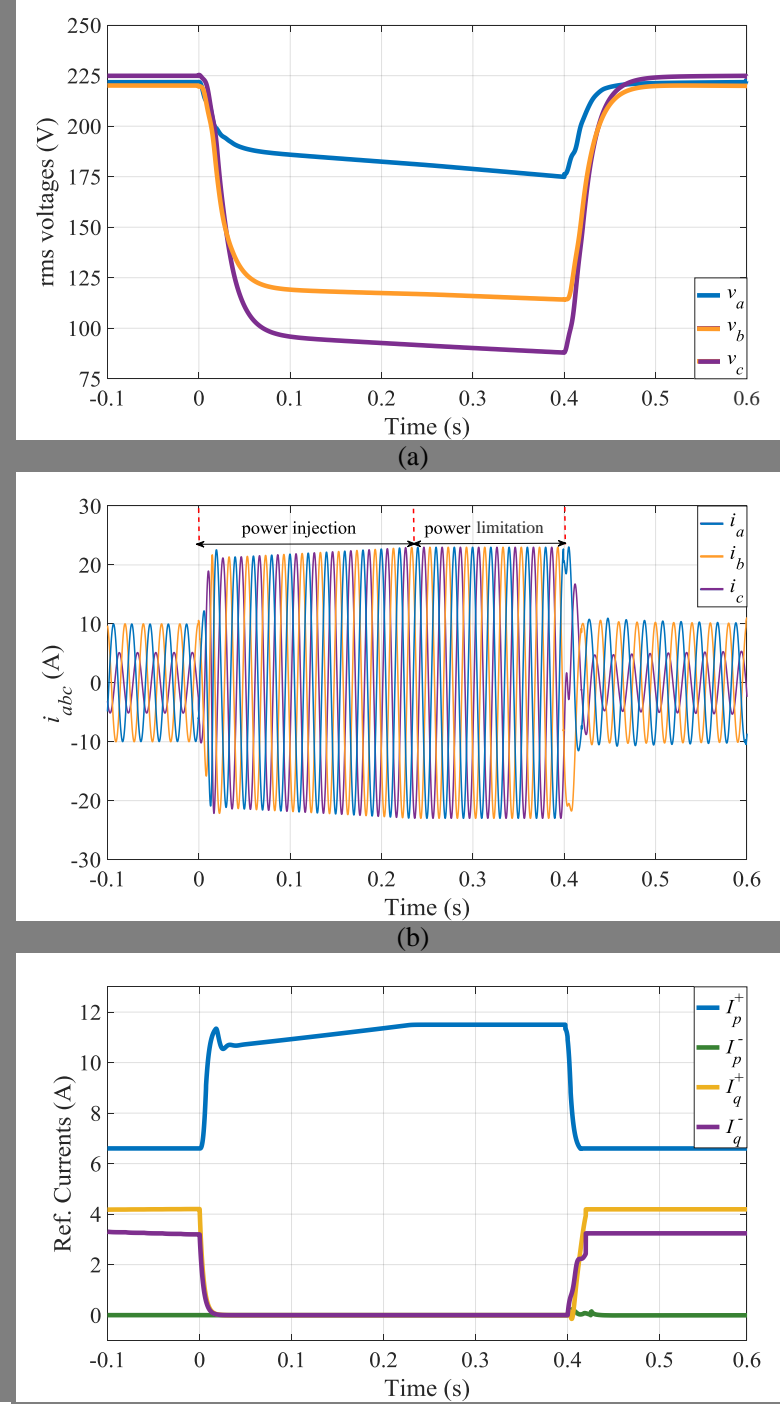

(c)

Fig. 17. Dynamic performance of the voltage support proposal against a voltage sag in Test 1 , (a) phase rms voltages, (b) phase currents injected by the inverter, (c) reference currents.

normal operation, the voltage values coincide with those selected for Test 1 . At $t=0$, a voltage sag with variable profile starts and, at $\mathrm{t}=0.4 \mathrm{~s}$, the sag is cleared. Fig. 17 (b) and (c) show the instantaneous and reference currents, respectively. During the sag, two time intervals can be clearly observed. In the first interval, the injected currents are lower than Isc, thus maintaining the injection of the generated power. The currents are increasing in this interval since the positive-sequence voltage is decreasing. In the second interval, the amplitude of the injected currents coincide with Isc and the positivesequence voltage continues decreasing, thus the active power limitation mechanism is activated. In this case, the active power is lower than the generated power.

\section{CONCLUSION}

A communication-less voltage support control scheme for inverter-based DG systems has been presented in this paper to mitigate the problem of voltage imbalance. The control scheme 
has been derived taking into account the following objectives: 1) to increase the positive sequence voltage, 2) to decrease the negative sequence voltage, 3 ) to inject the generated power, and 4) to minimize the output current. A control algorithm that simultaneously achieves these control objectives has been presented. Selected experimental results have been reported to validate the performance and robustness of the proposed control strategy. The most prominent feature is that the voltage imbalance can be reduced to values lower than those specified by the standards. This feature is achieved while the control objectives associated with the injection of power and current are maintained.

\section{APPENDIX}

This Appendix shows the equations that relate the amplitudes of the phase voltages, currents and their corresponding angles. The amplitude of the phase voltages can be obtained from the positive $V^{+}$and negative $V^{-}$sequence voltages, and the angle between them $\varphi_{V}$ as [19], [21]

$$
\begin{gathered}
V_{a}=\sqrt{\left(V^{+}\right)^{2}+\left(V^{-}\right)^{2}+2 V^{+} V^{-} \cos \left(\varphi_{V}\right)} \\
V_{b}=\sqrt{\left(V^{+}\right)^{2}+\left(V^{-}\right)^{2}+2 V^{+} V^{-} \cos \left(\varphi_{V}-2 / 3 \pi\right)} \\
V_{c}=\sqrt{\left(V^{+}\right)^{2}+\left(V^{-}\right)^{2}+2 V^{+} V^{-} \cos \left(\varphi_{V}+2 / 3 \pi\right)}
\end{gathered}
$$

Similarly, the phase currents amplitudes are [21]

$$
\begin{gathered}
I_{a}=\sqrt{\left(I^{+}\right)^{2}+\left(I^{-}\right)^{2}+2 I^{+} I^{-} \cos \left(\varphi_{I}\right)} \\
I_{b}=\sqrt{\left(I^{+}\right)^{2}+\left(I^{-}\right)^{2}+2 I^{+} I^{-} \cos \left(\varphi_{I}-2 / 3 \pi\right)} \\
I_{c}=\sqrt{\left(I^{+}\right)^{2}+\left(I^{-}\right)^{2}+2 I^{+} I^{-} \cos \left(\varphi_{I}+2 / 3 \pi\right)}
\end{gathered}
$$

where

$$
\begin{gathered}
I^{+}=\sqrt{\left(I_{p}^{+}\right)^{2}+\left(I_{q}^{+}\right)^{2}} \\
I^{-}=\sqrt{\left(I_{q}^{-}\right)^{2}+\left(I_{q}^{-}\right)^{2}} \\
\varphi_{I}=-\varphi_{V}+\operatorname{atan} 2\left(I_{q}^{+}, I_{p}^{+}\right)+\operatorname{atan} 2\left(I_{q}^{-}, I_{q}^{-}\right) .
\end{gathered}
$$

\section{REFERENCES}

[1] C. L. Masters. (2002, Feb.). Voltage rise: the big issue when connecting embedded generation to long $11 \mathrm{kV}$ overhead lines. Inst. Elect. Eng. Power Eng. J. [Online]. 16 (1), pp. 5-12. Available: https://ieeexplore.ieee.org/document/990181

[2] A. V. Jouanne and B. Banerjee. (2001, Oct.). Assessment of voltage unbalance. IEEE Trans. Power Del. [Online]. 16 (4), pp. 782-790. Available: https://ieeexplore.ieee.org/document/956770

[3] M. Kipness. (2008, Feb.). IEEE standard for interconnecting distributed resources with electric power systems. IEEE Std. [Online]. 1547. Available: https://standards.ieee.org/standard/1547-2003.html

[4] A. Yepes, A. Vidal, O. Lopez, and J. Doval-Gandoy. (2014, Jul.). Evaluation of techniques for cross-coupling decoupling between orthogonal axes in double synchronous reference frame current control. IEEE Trans. Ind. Electron. [Online]. 61 (7), pp. 3527-3531. Available: https://ieeexplore.iee.org/document/956770

[5] M. M. Shabestary and Y. A. R. I. Mohamed. (2018, Feb.). Advanced voltage support and active power flow control in grid-connected converters under unbalanced conditions. IEEE Trans. on Power Electron. [Online]. $33 \quad$ (2), pp. 1855-1864. Available: https://ieeexplore.ieee.org/document/7904738

[6] M. Castilla, J. Miret, A. Camacho, L. García de Vicuña and J. Matas. (2014, Nov.). Modeling and design of voltage support control schemes for three-phase inverters operating under unbalanced grid conditions. IEEE Trans. on Power Electron. [Online]. 29 (11), pp. 6139-6150. Available: https://ieeexplore.ieee.org/document/6698312

[7] Z. Dai, H. Lin, H. Yin and Y. Qiu. (2015, Aug.). A novel method for voltage support control under unbalanced grid faults and grid harmonic voltage disturbances. IET Power Electronics [Online]. 8 (8), pp. 13771385. Available: https://ieeexplore.ieee.org/document/7166479

[8] T. Lee, S. Hu, and Y. Chan. (2013, Apr.). D-STATCOM with positivesequence admittance and negative-sequence conductance to mitigate voltage fluctuations in high-level penetration of distributed generation systems. IEEE Trans. Ind. Electron [Online]. 60 (4), pp. 1417-1428. Available: https://ieeexplore.ieee.org/document/6003779

[9] J. Sosa, M. Castilla, J. Miret, J. Matas, and Y. A. Al-Turki. (2016, Apr.). Control strategy to maximize the power capability of PV three-phase inverters during voltage sags. IEEE Trans. Power Electron. [Online]. 31 (4), pp. 3314-3323. Available: https://ieeexplore.ieee.org/document/7145468

[10] S. K. Chaudhary, R. Teodorescu, P. Rodriguez, P. C. Kjær, and A. Gole. (2012, Jul.). Negative sequence current control in wind power plants with VSC-HVDC connection. IEEE Trans. Sustain. Energy. [Online]. 3 (3), pp. 535-544. Available: https://ieexplore.iee.org/document/6193197

[11] A. Moawwad, M. S. E. Moursi, and W. Xiao (2016, Nov.). Advanced fault ride-through management scheme for VSC-HVDC connecting offshore wind farms," IEEE Trans. Power Syst. [Online]. 31 (6), pp. 4923-4934. Available: https://ieeexplore.ieee.org/document/7423825

[12] A. Vidal, F. D. Freijedo, A. G. Yepes, P. Fernandez-Comesana, J. Malvar, O. Lopez, and J. Doval-Gandoy. (2013, Apr.). Assessment and optimization of the transient response of proportional-resonant current controllers for distributed power generation systems, IEEE Trans. Ind. Electron. $\quad 60 \quad(4), \quad$ pp. 1367-1383. Available: https://ieeexplore.ieee.org/document/6153368

[13] S. Alepuz, S. Busquets-Monge, J. Bordonau, J. A. Martinez-Velasco, C. A. Silva, J. Pont, and J. Rodriguez. (2009, Jun.). Control strategies based on symmetrical components for grid-connected converters under voltage dips. IEEE Trans. Ind. Electron. [online]. 56 (6), pp. 2162-2173. Available: https://ieeexplore.ieee.org/document/4801749

[14] A. Vidal, A. G. Yepes, F. D. Freijedo, O. López, J. Malvar, F. Baneira, and J. Doval-Gandoy. (2015, Dec). A method for identification of the equivalent inductance and resistance in the plant model of currentcontrolled grid-tied converters. IEEE Trans. Power Electron. [online]. 30 (12), pp. 7245- $7261 . \quad$ Available: https://ieeexplore.ieee.org/document/7018048

[15] F. Wang, J. L. Duarte, and M. A. M. Hendrix. (2011 May). Pliant active and reactive power control for grid-interactive converters under unbalanced voltage dips. IEEE Trans. on Power Electron. Journal. [online]. 26 (5), pp. 1511-1521. Available: https://ieeexplore.ieee.org/document/5482131

[16] C.-T. Lee, C.-W. Hsu, and P.-T. Cheng. (2011, Jul). A low-voltage ridethrough technique for grid-connected converters of distributed energy resources. IEEE Trans. Ind. Appl. [online]. 47 (4), pp. 1821-1832. Available: https://ieeexplore.iee.org/document/5770209

[17] M. Castilla, J. Miret, A. Camacho, J. Matas, and L. García de Vicuña. (2014, Feb.). Voltage support control strategies for static synchronous compensators under unbalanced voltage sags. IEEE Trans. Ind. Electron. [online]. $61 \quad(2), \quad$ pp. 808-820. Available: https://ieeexplore.ieee.org/document/6494616

[18] X. Du, Y. Wu, S. Gu, H. M. Tai, P. Sun, and Y. Ji. (2016, Jul.). Power oscillation analysis and control of three-phase grid-connected voltage source converters under unbalanced grid faults. IET Power Electronics [online]. 9 (11), pp. 2162-2173. Available: https://ieeexplore.ieee.org/document/7564592

[19] J. Miret, A. Camacho, M. Castilla, J. L. G. de Vicuña, and J. de la Hoz. (2015, Jun.). Reactive current injection protocol for low-power rating distributed generation sources under voltage sags. IET Power Electronics [online]. $\quad 8(6) . \quad$ pp. 879-886. Available: https://ieeexplore.iee.org/document/7115307

[20] M. Mirhosseini, J. Pou, and V. G. Agelidis. (2015, Oct.). Individual phase current control with the capability to avoid overvoltage in grid-connected photovoltaic power plants under unbalanced voltage sags. IEEE Trans. 
Power Electron. [online]. 30(10). pp. 5346-5351 Available: https://ieeexplore.ieee.org/document/7055366

[21] A. Camacho, M. Castilla, J. Miret, R. Guzman, and A. Borrell. (2014, Nov.). Reactive power control for distributed generation power plants to comply with voltage limits during grid faults. IEEE Trans. Power Electron. [online]. 29(11). pp. 6224-6234. Available: https://ieeexplore.ieee.org/document/6716987

[22] F. Sulla, J. Svensson, and O. Samuelsson. (2013, Jul.). Wind turbines voltage support in weak grids. IEEE Power Energy Soc. General Meeting. [online]. $\quad$ pp. 1-5. https://ieeexplore.ieee.org/document/6672130

[23] X. Guo, X. Zhang, B. Wang, W. Wu, and J. M. Guerrero. (2014, Mar.). Asymmetrical grid fault ride-through strategy of three-phase gridconnected inverter considering network impedance impact in low-voltage grid. IEEE Trans. Power Electron. [online]. 29(3). pp. 1064-1068. Available: https://ieeexplore.ieee.org/document/6587279

[24] W. Jiang, Y. Wang, J. Wang, L. Wang, and H. Huang. (2016, Oct.) Maximizing instantaneous active power capability for PWM rectifier under unbalanced grid voltage dips considering the limitation of phase current. IEEE Trans. Ind. Electron. [online]. 63(10). pp. 5998-6009. Available: https://ieeexplore.ieee.org/document/7486088

[25] A. Camacho, M. Castilla, J. Miret, L. G. de Vicuña and R. Guzman. (2018, Jun.). Positive and negative sequence control strategies to maximize the voltage support in resistive-inductive grids during grid faults. IEEE Trans. on Power Electron. [online]. 33(6). pp. 5362-5373. Available: https://ieeexplore.ieee.org/document/7994649

[26] P. Rodriguez, J. Pou, J. Bergas, J.I. Candela, R.P. Burgos, and D. Boroyevich. (2007, Mar.). Decoupled double synchronous reference frame PLL for power converters controls. IEEE Trans. Power Electron. [online]. 22(2). pp. 584-592. Available: https://ieeexplore.ieee.org/document/4118328

[27] S. Vazquez, J. Sanchez, M. Reyes, J. Leon, and J. Carrasco. (2014, Mar.) Adaptive vectorial filter for grid synchronization of power converters under unbalanced and/or distorted grid conditions. IEEE Trans. Ind. Electron. [online]. 61(3). pp. 1355-1367. Available: https://ieeexplore.ieee.org/document/6502704/

[28] O. Goksu, R. Teodorescu, C. L. Bak, F. Iov, and P. C. Kjær. (2013, Sep.). Impact of wind power plant reactive current injection during asymmetrical grid faults. IET Renewable Power Generation. [online]. 7(5). $\quad$ pp. 484-492. Available: https://ieeexplore.ieee.org/document/6584914/

[29] S. Kincic, X. Wan, D. T. McGillis, A. Chandra, B.-T. Ooi, F. D. Galiana, and G. Joos. (2005, Apr.). Voltage support by distributed static VAr systems (SVS). IEEE Trans. Power Del. [online]. 20(2). pp. 1541-1549. Available: https://ieeexplore.ieee.org/document/1413424

[30] R. Erickson and D. Maksimovic, "Fundamentals of power electronics," Ed. Kluver Academic Publishers, 2nd edition. Ed. Kluver Academic Publishers, 2011. 